\title{
Self-photopumped x-ray lasers from elements in the Ne-like and Ni-like ionization state
}

\author{
Michael Siegrist, Felix Staub, Fei Jia, Thomas Feurer, and Jürg Balmer \\ Institute of Applied Physics, University of Bern, Sidlerstrasse 5, Switzerland \\ Joseph Nilsen \\ Lawrence Livermore National Laboratory, Livermore, California 94551
}

\begin{abstract}
We report on experiments on the self-photopumped $3 \mathrm{~d}^{1} \mathrm{P}_{1} \rightarrow 3 \mathrm{p}{ }^{1} \mathrm{P}_{1}$ and $4 \mathrm{f}^{1} \mathrm{P}_{1} \rightarrow 4 \mathrm{~d}^{1} \mathrm{P}_{1}$ laser transitions in Ne-like and Ni-like ions, respectively. Lasing on the self-photopumped laser line has been observed for the first time for a number of elements including $\mathrm{Ne}$-like $\mathrm{V}, \mathrm{Cr}, \mathrm{Fe}$, and $\mathrm{Co}$ as well as Ni-like $\mathrm{Ru}$ and $\mathrm{Pd}$. We have investigated the lasing process by varying the prepulse delay, which shows a shift of the optimum main pulse to second prepulse delays towards lower values with higher atomic number Z. Time-resolved measurements showed that self-photopumped and monopole collision-pumped lasing emission occurs essentially simultaneously. Accurate wavelength measurements and calculations are shown to be in excellent agreement.
\end{abstract}

\section{Introduction}

Among the numerous schemes proposed over the years to achieve x-ray laser amplification [1], electron-collision-pumped x-ray lasers in Ne-like and Ni-like ions have undergone the most impressive development in terms of efficiency, short wavelength, and repetition rate. The enormous progress is best documented by the recent demonstration of $100-\mathrm{Hz}$ operation of soft-x-ray lasers at sub-15-nm in Ni-like silver and tin [2], or the achievement of saturated soft-x-ray lasing at $7.3 \mathrm{~nm}$ in Ni-like samarium [3]. Both these results were obtained with picosecond laser drivers, making use of the prepulse technique [4] in the grazing-incidence pumping (GRIP) configuration [5]. The strongest lines for most Ne-like and Ni-like x-ray lasers have been the $3 \mathrm{p}^{1} \mathrm{~S}_{0} \rightarrow 3 \mathrm{~s}^{1} \mathrm{P}_{1}$ and $4 \mathrm{~d}^{1} \mathrm{~S}_{0} \rightarrow 4 \mathrm{p}{ }^{1} \mathrm{P}_{1}$ transitions (the $\mathrm{J}=0-1$ lines), respectively, which are pumped by electron collisions. Other lines lasing due to collisional excitation, recombination from the next-higher ionization state, and cascades from higher levels were also observed, but usually much weaker. However, in some of the experiments on Ne-like lasing an additional strong line was observed (45.1 nm in $\operatorname{Ar}$ [6], $30.1 \mathrm{~nm}$ in Ti [7]) that could not be attributed to any of the known $3 p \rightarrow 3 s$ transitions. Numerical simulations later revealed it to be a $3 \mathrm{~d} \rightarrow 3 \mathrm{p}$ transition in the Ne-like ions, more precisely the $3 \mathrm{~d}^{1} \mathrm{P}_{1} \rightarrow 3 \mathrm{p}$ ${ }^{1} \mathrm{P}_{1}$ transition, with the excitation mechanism identified as being due to self-photopumping [810]. It was predicted that this scheme should also work for other Ne-like ions as well as for Ni-like ions, where the analogous transition is the $4 \mathrm{f}^{1} \mathrm{P}_{1} \rightarrow 4 \mathrm{~d}^{1} \mathrm{P}_{1}$ transition [11]. Experimentally, lasing on this transition has been demonstrated for $\mathrm{Zr}(Z=40), \mathrm{Nb}(Z=41), \mathrm{Mo}(\mathrm{Z}$ $=42)$, and $\operatorname{Ag}(Z=47)$ at wavelengths of $27.1,24.6,16.1$, and $22.6 \mathrm{~nm}$, respectively $[12,13]$. The self-photopumped $x$-ray lasers may be regarded as an alternative scheme to electron collisional excitation in the search for an extension of available XUV and soft-x-ray laser wavelengths. In addition, while the self-photopumped laser line suffers from somewhat lower gain compared to the electron-collision-pumped line, its higher saturation intensity gives it the potential of becoming the most intense lasing line [14]. It is interesting to note, here, that it has been shown to be possible to seed both collisional and the self-photopumped lines simultaneously [15]. 
In this paper, we report on first-time observation of lasing on the $3 \mathrm{~d}^{1} \mathrm{P}_{1} \rightarrow 3 \mathrm{p}{ }^{1} \mathrm{P}_{1}$ and the $4 \mathrm{f}$ ${ }^{1} \mathrm{P}_{1} \rightarrow 4 \mathrm{~d}^{1} \mathrm{P}_{1}$ lines for $\mathrm{V}, \mathrm{Cr}, \mathrm{Fe}, \mathrm{Co}(\mathrm{Ne}-$ like) and $\mathrm{Ru}, \mathrm{Pd}$, and $\mathrm{Ag}$ (Ni-like) and present accurate wavelength measurements for these elements (except for $\mathrm{Co}$ ). For several elements including Ne-like Ti, $\mathrm{V}$, and $\mathrm{Cr}$ as well as Ni-like $\mathrm{Mo}$ and $\mathrm{Ru}$ we present measurements of the timing of the self-photopumped lasing with respect to the collision-pumped $\mathrm{J}=0-1$ line. This will be useful for improving the modeling and understanding of the self-photopumping process.

\section{Principle of self-photopumping}

Here, we restrict ourselves to a short summary of the most relevant aspects of the mechanism of self-photopumping in Ne-like and Ni-like lasers, which have previously been described and analyzed in detail in a number of papers [9, 12 and refs. therein]. Fig. 1 shows the simplified energy diagrams of the Ne-like (left) and Ni-like (right) ionization states with the important levels and transitions involved (for convenience, we omitted the $1 \mathrm{~s}^{2} 2 \mathrm{~s}^{2} 2 \mathrm{p}^{5}$ electrons for Nelike and the $1 s^{2} 2 s^{2} 2 p^{6} 3 s^{2} 3 p^{6} 3 d^{9}$ electrons for Ni-like ions which are common to all the levels). The $3 \mathrm{p}^{1} \mathrm{~S}_{0} \rightarrow 3 \mathrm{~s}^{1} \mathrm{P}_{1}$ (Ne-like) and $4 \mathrm{~d}^{1} \mathrm{~S}_{0} \rightarrow 4 \mathrm{p}{ }^{1} \mathrm{P}_{1}$ (Ni-like) laser lines are preferentially pumped by monopole electron collisions from the $2 \mathrm{p}{ }^{1} \mathrm{~S}_{0} \mathrm{Ne}$-like $\left(3 \mathrm{~d}{ }^{1} \mathrm{~S}_{0}\right.$ for Ni-like) ground state (the well-known " $\mathrm{J}=0-1$ " lines).

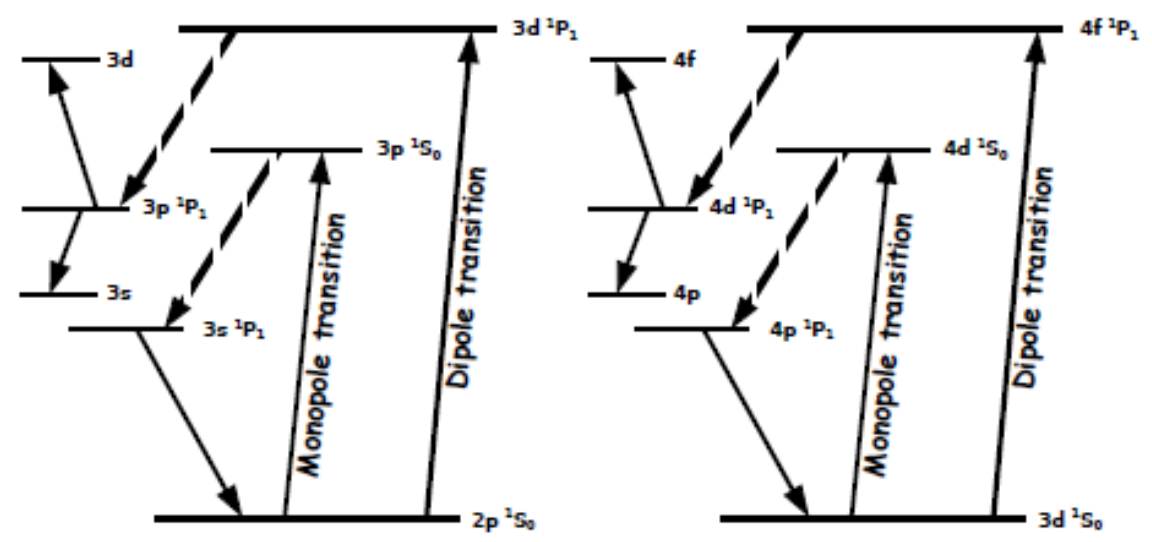

Figure 1. Level diagram for the Ne-like (left) and Ni-like (right) ionization state respectively. The dashed lines indicate the self-photopumped and monopole collision-pumped laser transitions, respectively.

Unlike for collisional excitation, the upper level of the self-photopumped line, the $3 \mathrm{~d}^{1} \mathrm{P}_{1}$ level ( $4 \mathrm{f}^{1} \mathrm{P}_{1}$ for Ni-like), is driven by a combination of collisional excitation and self-photopumping. The self-photopumping process is driven by the very intense $3 d^{1} \mathrm{P}_{1} \rightarrow 2 p{ }^{1} \mathrm{~S}_{0}$ resonance radiation $\left(4 \mathrm{f}^{1} \mathrm{P}_{1} \rightarrow 3 \mathrm{~d}^{1} \mathrm{~S}_{0}\right.$ for Ni-like). This is possible because the plasma is optically thick for this line, so that radiation trapping (or reabsorption [14]) becomes very strong. The population inversion is preserved due to depopulation of the lower level by collisional mixing with the other nearby $3 \mathrm{~s}$ and $3 \mathrm{~d}$ levels $(4 \mathrm{p}$ and $4 \mathrm{f}$ for Ni-like). Self-photopumped $\mathrm{x}$-ray lasers have been shown before for $\mathrm{Ne}$-like $\mathrm{Ti}$ and $\mathrm{Ar}$ as well as for Ni-like $\mathrm{Zr}$, $\mathrm{Nb}$ and $\mathrm{Mo}[6,7,12]$. In all cases, the wavelengths of the self-photopumped lines are lower than the collision-pumped $\mathrm{J}=0-1$ wavelengths for Ne-like ions, but higher for Ni-like ions. Here, we demonstrate several new elements to lase on this line, namely Ne-like V, Cr, Fe and Co as well as Ni-like $\mathrm{Ru}, \mathrm{Pd}$ and Ag. 


\section{Experimental setup - the BeAGLE System}

The experiments were conducted using the existing 1054-nm Nd:glass CPA laser system (BeAGLE facility) that is capable of providing a maximum output energy of $\sim 20 \mathrm{~J}$ in a 1.5 -ps duration pulse at a rate of 1 shot every 25 minutes. The system is used to irradiate targets of the various elements in the grazing-incidence pumping (GRIP) scheme at an angle of $50^{\circ}$, with a traveling-wave speed of $\sim 0.95 \mathrm{c}[16]$. For the self-photopumping experiments we used a two-prepulse configuration by inserting beam splitters having reflectivities of $0.5,2.8,4.5,8$ or $16 \%$ as in previous experiments. This scheme has the advantage that the prepulses are propagating along the same path as the main pulse, thus minimizing the variations in pulse overlap at the line focus.

The main diagnostics of the soft x-ray emission from the plasma is an on-axis, time-integrating XUV spectrometer that consists of a 1200-lines/mm, aberration-corrected Hitachi grating (radius of curvature: $5649 \mathrm{~mm}$ ), working at a grazing-incidence angle of $3^{\circ}$. The grating disperses the incident radiation onto a 40-mm diameter P20 phosphor screen, which is imaged to a cooled CCD camera having a pixel size of $23 \times 23 \mu \mathrm{m}^{2}$. The wavelength coverage of the spectrometer is $\sim 5-25 \mathrm{~nm}$ with a spectral resolution of $\sim 0.2 \mathrm{~nm}$. The relatively poor resolution is a consequence of the slitless operation of the spectrometer, which results in the measured linewidths being dominated by source broadening. This configuration of the spectrometer was used for the measurements on prepulse optimization discussed in Section 4.

For the time-resolved measurements discussed in Section 5, the P20 phosphor was replaced by a Kentech $\times 2$-magnification $\mathrm{x}$-ray streak camera having a $140-\mu \mathrm{m}$ wide entrance slit. The streak camera was equipped with a transmission photocathode made of a 1200 - $\AA$ thick layer of CsI deposited on a $1200-\AA$ thick Formvar foil. The streaked signal is read out by an image intensifier coupled to the cooled CCD camera. To avoid saturation of the streak camera, a 10$\mu \mathrm{m}$ wide slit and several Al-on-Formvar filters were inserted at the entrance of the spectrograph. The (instrumental) time resolution of the streak camera was $\sim 15 \mathrm{ps}$. However, the temporal resolution among spectrally separated signals not overlapping on the streaked image reaches $\sim 2$ ps.

For the precision wavelength measurements discussed in Section 6, several modifications to the diagnostics were introduced in order to improve the spectral resolution of the system: the spectrograph was equipped with an adjustable entrance slit and the (de)magnification of the optics imaging the phosphor to the CCD camera was changed from 4:1 to 1:1. After replacing the CCD camera with a camera having smaller pixel size $\left(9 \times 9 \mu \mathrm{m}^{2}\right)$, a 10 -fold increase in spectral resolution per pixel and a relative spectral accuracy of $\pm 0.01 \mathrm{~nm}$ were achieved.

\section{Optimization of the prepulse delays}

As is well known from previous experiments, the prepulse configuration of the laser system is crucial to the optimization of the x-ray laser output. The experiments on self-photopumped xray lasers under consideration here have been performed with a triple-pulse scheme similar to the one used in our previous experiments [17]. Here it consisted of a $0.5 \%$ first prepulse, preceding the main pulse by $5 \mathrm{~ns}$, and a $16 \%$ beam splitter for the second prepulse, at variable delay. The total energy of the three pulses was $\sim 3$ J. Fig. 2 shows a typical $x$-ray spectrum obtained from a Ti target irradiated under these conditions. The image on the left side of fig. 2 is logarithmically scaled in order to make the faint spontaneous emission visible. The graph to the right is a linearly scaled scan to the spectral image.

Clearly, the spectrum is dominated by two lasing lines: the monopole electron-collisionpumped $\mathrm{J}=0-1$ line at $32.6 \mathrm{~nm}$ and the self-photopumped $3 \mathrm{~d}^{1} \mathrm{P}_{1} \rightarrow 3 \mathrm{p}{ }^{1} \mathrm{P}_{1}$ line at $30.1 \mathrm{~nm}$. For this shot, the second prepulse preceded the main pulse by $500 \mathrm{ps}$. 

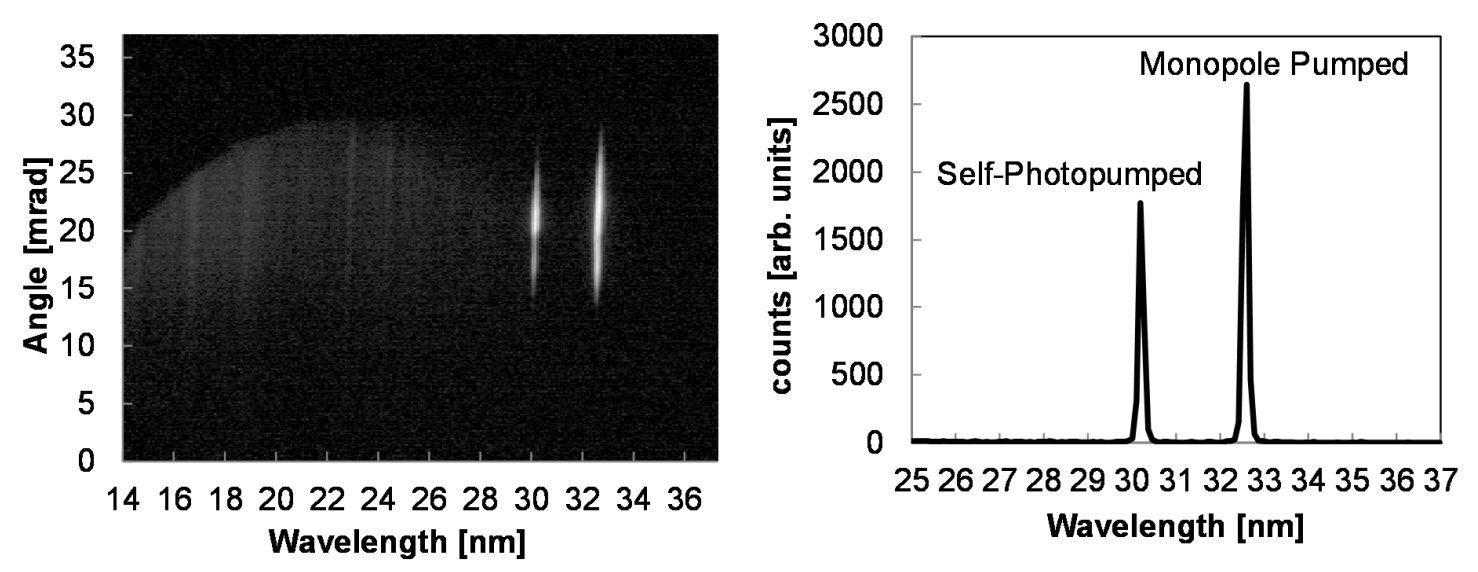

Figure 2. Raw image (left) and the corresponding lineout spectrum (right) clearly showing the two distinct lines for the monopole and the self-photopumped lasing lines for Ne-like Ti. The intensity of the image (left) is scaled logarithmically to make the faint spontaneous emission visible.

On the course of the experiments, it was observed that the timing of the first prepulse (3-5 ns before the main pulse) had only a minor effect on the x-ray laser output. In contrast to this, the main pulse-to-second prepulse delay has been found to be the crucial parameter for selfphotopumped lasing. A series of measurements was therefore undertaken in order to find the optimum delay conditions for the second prepulse. Fig. 3 shows the results for Ne-like Ti and $\mathrm{V}$ as well as Ni-like Mo and Pd.

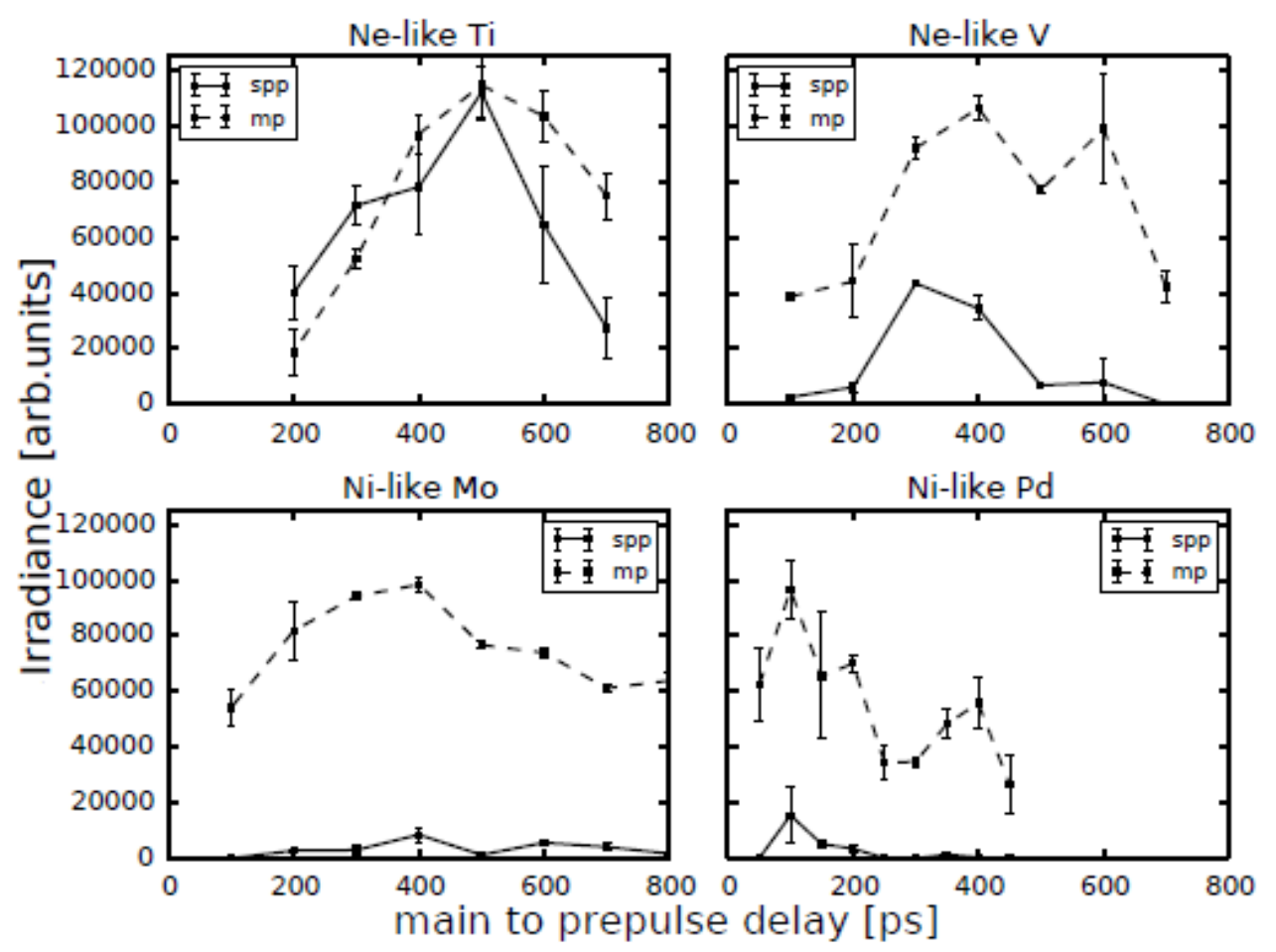

Figure 3. Dependence of the self-photopumped (spp) and the monopole electroncollision-pumped (mp) laser output irradiance on the main-to-second prepulse delay. The second prepulse had $22.7 \%$ of the main pulse energy. The solid and dashed lines are there to guide the eye. 
The measurements were performed for Ne-like Ti, V, Cr, Fe and $\mathrm{Co}$ as well as for Ni-like Mo, $\mathrm{Ru}, \mathrm{Pd}$ and $\mathrm{Ag}$. Nominally identical driver laser parameters as mentioned above were used for all the measurements, except for $\mathrm{Ne}-\mathrm{like} \mathrm{Fe}$ and $\mathrm{Co}$, where the total energy was increased to 11 and $15 \mathrm{~J}$, respectively, with a $2.8 \%$ first prepulse preceding the main pulse by 4 ns. Fig. 4 shows a plot of the optimum delay for each of these elements versus the atomic number $Z$. Clearly, with increasing Z, a shift towards smaller delays is observed for both the Ne-like and the Ni-like ionization scheme. The optimum delay seems to converge to a value around $100 \mathrm{ps}$ for both the Ne-like and Ni-like lasing schemes. A similar behavior has been observed in monopole electron-collision-pumped lasing of the Ni-like scheme, where the optimum delay for the second prepulse decreases from $\sim 100 \mathrm{ps}$ for $\mathrm{Sn}$ to $\sim 25 \mathrm{ps}$ for La [17]. This might be attributed to the increase in optimum electron density and temperature with increasing $\mathrm{Z}$, demanding for less expanded plasma and thus shorter prepulse delays. Interestingly, for the self-photopumped lines, lasing has not been observed here for delays smaller than $100 \mathrm{ps.}$
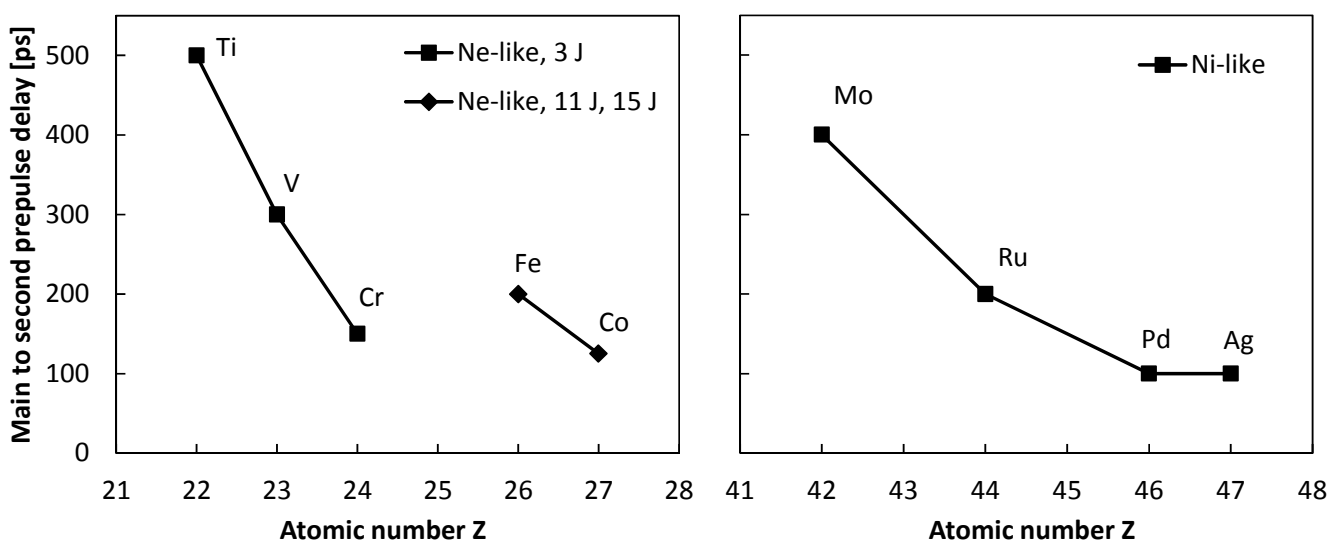

Figure 4. Dependence of the optimum main-to-second prepulse delay on atomic number $\mathrm{Z}$. The measurements for $\mathrm{Fe}$ and $\mathrm{Co}$ in the left figure were taken at higher pump energy.

\section{Divergence}

The measurements described in section 4 were also used to derive the divergence angle of the monopole collision-pumped and self-photopumped laser emission in the plane perpendicular to the target. The results are summarized in fig. 5. The values shown are the FWHM's of the Gaussian fits to the scans of the spectra in angular direction. The error bars represent the standard deviation of the fitted values. It was found that the divergence of monopole collisionpumped lasing exceeds the divergence of self-photopumped lasing by roughly $2 \mathrm{mrad}$ for all elements investigated. This may be interpreted as an indication that the lateral size of the gain zone is somewhat smaller for self-photopumped than for monopole collision-pumped lasing.

A comparison of the emission angles of monopole collision-pumped and self-photopumped lasing shows a less consistent image. Despite the fact that there is a significant difference in emission angle $\Delta \varphi$ between monopole collision-pumped and self-photopumped lasing for some elements, $\Delta \varphi$ varies between $\sim \pm 2 \mathrm{mrad}$ for nickel-like elements and $\sim \pm 1 \mathrm{mrad}$ for neonlike elements and seems to be dominated by the specific pump configuration of each element rather than following a general trend. More precise conclusions would have required the implementation of an angular fiducial, which was not the case in this series of experiments. 


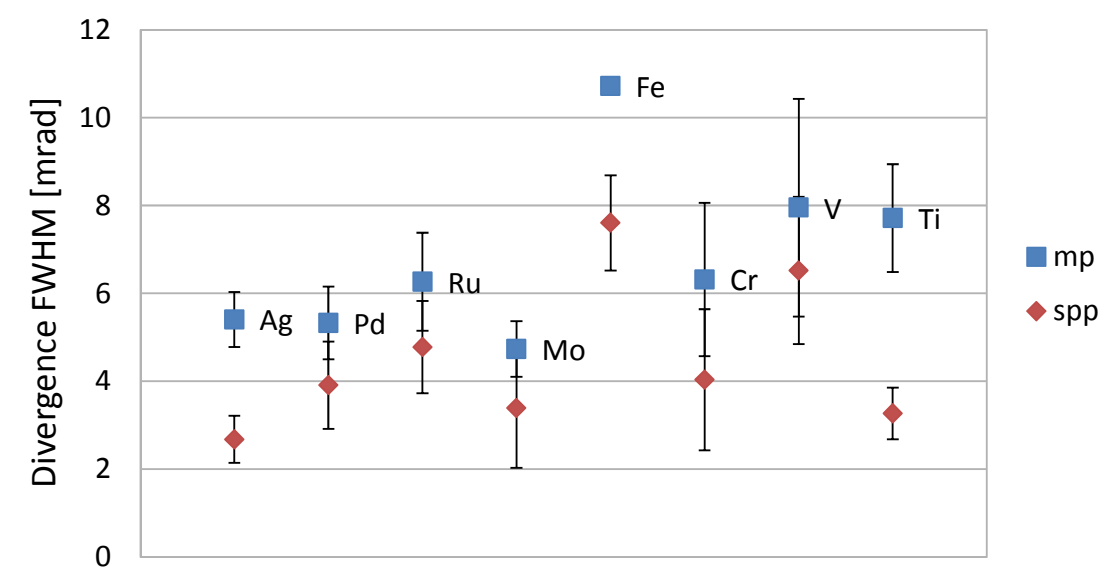

Figure 5. FWHM divergence of the monopole collision-pumped (mp) and selfphotopumped (spp) laser emission, respectively, measured in the plane perpendicular to the target surface. The self-photopumped lasing line shows smaller divergence than the monopole collision-pumped line for all elements.

\section{Time of lasing}

In order to get a better understanding of the self-photopumped lasing process, the time of lasing with respect to the electron-collision-pumped lasing line is of great interest. As mentioned above, time-resolved measurements were performed with a Kentech $\times 2$-magnification $\mathrm{x}$-ray streak camera having a $140-\mu \mathrm{m}$ wide and $18-\mathrm{mm}$ long entrance slit. The camera was mounted with the aid of a sliding mount in such a way that it could be shifted along the focal plane of the spectrometer to cover the desired spectral window. In order to minimize space-charge effects in the streak tube, measurements were taken at lowest possible intensities at the photocathode. Fig. 6 shows the streak camera recording (raw data) of a shot showing the streaked signals of the self-photopumped $4 \mathrm{f}^{1} \mathrm{P}_{1} \rightarrow 4 \mathrm{~d}^{1} \mathrm{P}_{1}$ (top at $19.4 \mathrm{~nm}$ ) and the monopole collisionpumped $4 \mathrm{~d}^{1} \mathrm{~S}_{0} \rightarrow 4 \mathrm{p}^{1} \mathrm{P}_{1}$ (bottom at $16.5 \mathrm{~nm}$ ) lines for Ni-like $\mathrm{Ru}$. The intensity of this image is logarithmically scaled in order to render the faint spontaneous emission visible. Interestingly, the pre- and post-pulse originating from the second prepulse plate are sufficient to cause monopole collision-pumped lasing for this shot (emission located at $\pm 200 \mathrm{ps}$ on the 16.5-nm line), a fact that was used for double-checking the sweep-speed calibration. At the time of peak of the main pulse $(\mathrm{t}=0)$, self-photopumped and strongest monopole collisionpumped emissions occur, along with a continuum of spontaneous emission (faint vertical trace around $t=0$ in fig. 6 ). The curvature of the latter reveals severe image distortion caused by the streak tube electron optics. This effect was corrected for numerically in the image analysis.

The results of the timing measurements are summarized in Table I, where $\Delta t$ denotes the difference in emission time between self-photopumped and monopole collision-pumped lasing (negative $\Delta \mathrm{t}$ meaning that self-photopumped occurs before monopole collision-pumped lasing) and $\sigma \Delta \mathrm{t}$ is the estimated error. The error is an orthogonal combination of the standard deviation of the measurements and the uncertainty of the fitted image distortion. Except for vanadium, the results indicate that self-photopumped lasing occurs slightly before monopole 
collision-pumped lasing. However, as the errors are of the same order of magnitude as $\Delta \mathrm{t}$, we may conclude that, within the error of the measurement, monopole collision-pumped and selfphotopumped lasing occur simultaneously.

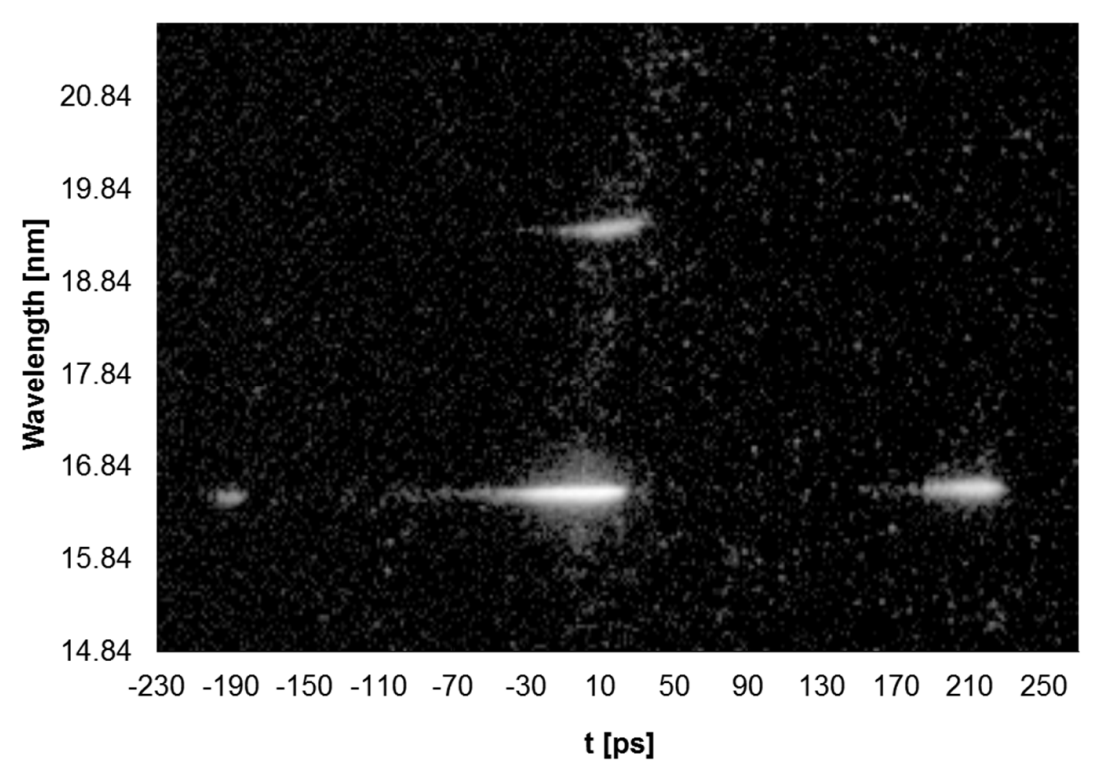

Figure 6. Logarithmically scaled streak camera recording (raw data), clearly showing the streaked signals of the self-photopumped $4 \mathrm{f}^{1} \mathrm{P}_{1} \rightarrow 4 \mathrm{~d}^{1} \mathrm{P}_{1}$ (top) and the monopole collision-pumped $4 \mathrm{~d}^{1} \mathrm{~S}_{0} \rightarrow 4 \mathrm{p}{ }^{1} \mathrm{P}_{1}$ (bottom) lines for Ni-like Ru.

Table I. Difference in emission time of monopole collision-pumped and self-photopumped lasing $(\Delta t)$ along with the estimated error $(\sigma \Delta t)$. Negative $\Delta t$ means that selfphotopumped lasing occurs before monopole collision-pumped.

\begin{tabular}{|c|c|c|}
\hline Element & $\Delta \mathrm{t}[\mathrm{ps}]$ & $\sigma \Delta \mathrm{t}[\mathrm{ps}]$ \\
\hline $\mathrm{Ti}$ & -2 & 2 \\
\hline $\mathrm{V}$ & 0 & 2 \\
\hline $\mathrm{Cr}$ & -1 & 2 \\
\hline $\mathrm{Mo}$ & -2 & 3 \\
\hline $\mathrm{Ru}$ & -3 & 2 \\
\hline
\end{tabular}




\section{Precision wavelength measurements}

Precision measurements of the wavelengths were conducted for the self-photopumped lines of Ni-like Ag, Pd, Ru, Mo and for Ne-like Fe, Cr, V and Ti. The measurements were performed using the setup described in section 3 . The spectra were calibrated against precision measurements of Ne-like $3 \mathrm{p}^{1} \mathrm{~S}_{0}-3 \mathrm{~s}{ }^{1} \mathrm{P}_{1}$ and the Ni-like $4 \mathrm{~d}{ }^{1} \mathrm{~S}_{0}-4 \mathrm{p}{ }^{1} \mathrm{P}_{1}$ monopole collisional lasing lines from Refs. 16 and 17 with the exception of Ni-like Ru that was measured in this work. These reference lines are produced in the same plasma as the self-photopumped lines. The reference line of $\mathrm{Ru}$ was measured in two different wavelength windows and calibrated against the fits of the $\mathrm{Sn}, \mathrm{Ag}$ and $\mathrm{Pd}$ lines in first order, and $\mathrm{Ag}, \mathrm{Cr}, \mathrm{Pd}, \mathrm{V}$ and Ti lines in second order, respectively. Four different wavelength windows were required to cover the whole spectral range of the self-photopumped lines listed in Tables II and III below. These were calibrated with up to 8 of the monopole collisional lasing lines from Refs. 18 and 19. The estimated error of the final self-photopumped wavelengths is a combination of the uncertainty of the location of the recorded spectral lines and the residues of the fits to the calibration lines. The results for the Ni-like lines are summarized in Table II. The number in parenthesis is the error of the least significant digit, i.e. in units of $10^{-3} \mathrm{~nm}$. It can be seen that the calculations of the Ni-like self-photopumped lines from Ref. 12 deviate from the measurements by less than $0.03 \mathrm{~nm}$.

Table II. Wavelengths of the self-photopumped Ni-like x-ray laser lines measured in this work. The uncertainties in the last digit are given in parentheses. The monopole collisional reference lines are from ${ }^{a}$ Ref. 18, except for Ru that was measured in this work. The calculations of the Ni-like self-photopumped lines are from ${ }^{\mathrm{b}} \mathrm{Ref} .12$.

\begin{tabular}{|c|c|c|c|}
\hline Ni-like & $\begin{array}{c}\text { Reference line } \\
4 \mathrm{~d}^{1} \mathrm{~S}_{0}-4 \mathrm{p}{ }^{1} \mathrm{P}_{1}(\mathrm{~nm})\end{array}$ & \multicolumn{2}{|c|}{$\begin{array}{r}\text { Self-photopumped line } \\
4 \mathrm{f}^{1} \mathrm{P}_{1}-4 \mathrm{~d}^{1} \mathrm{P}_{1}\end{array}$} \\
\hline & & Measurement (nm) & Calculation (nm) \\
\hline $\mathrm{Ag}$ & $13.892(15)^{\mathrm{a}}$ & $16.014(11)$ & $16.04^{\mathrm{b}}$ \\
\hline $\mathrm{Pd}$ & $14.679(15)^{\mathrm{a}}$ & $16.992(9)$ & $17.01^{\mathrm{b}}$ \\
\hline $\mathrm{Ru}$ & $16.523(11)$ & $19.397(7)$ & $19.41^{\mathrm{b}}$ \\
\hline $\mathrm{Mo}$ & $18.8953(15)^{\mathrm{a}}$ & $22.608(7)$ & $22.61^{\mathrm{b}}$ \\
\hline
\end{tabular}

Table III shows the measured value for the $3 \mathrm{~d}^{1} \mathrm{P}_{1}-3 p{ }^{1} \mathrm{P}_{1}$ self-photopumped laser lines for Ne-like Fe, Cr, V and Ti. In the experiment the wavelengths were calibrated against the fitted values for the strong Ne-like $3 p{ }^{1} \mathrm{~S}_{0}-3 \mathrm{~s}{ }^{1} \mathrm{P}_{1}$ laser lines from Ref. 19. To calculate the wavelengths of the $3 d^{1} \mathrm{P}_{1}-3 p{ }^{1} \mathrm{P}_{1}$ self-photopumped laser lines for $\mathrm{Ti}(\mathrm{Z}=22)$ to $\mathrm{Zn}(\mathrm{Z}=30)$ we used the multi-configuration Dirac-Fock (MCDF) atomic physics code of Grant et al. [20] in the extended average level (EAL) mode. As discussed in Ref. 12, there is typically a difference of almost $1 \mathrm{eV}$ between the calculated and measured values for laser lines because of mixing between the LS configurations for the lower laser states. The best direct measurement of a Ne-like self-photopumped lasing line is for Ti with a measured value of $30.15 \pm 0.05 \mathrm{~nm}$ given in Ref. 14. Using beam foil measurements, Buchet et al. [21] measured the energy 
levels for the $3 \mathrm{~d}^{1} \mathrm{P}_{1}$ upper and the $3 \mathrm{p}{ }^{1} \mathrm{P}_{1}$ lower states of the Ti laser transition. Since the $3 \mathrm{~d}$ ${ }^{1} \mathrm{P}_{1}$ upper laser level decays to the ground state as a strong resonance line this value is measured well with a value of $4281600 \mathrm{~cm}^{-1}$ that corresponds to an energy of $530.85 \mathrm{eV}$ and a wavelength of $2.3356 \mathrm{~nm}$. However there is considerable uncertainty in the value of the $3 \mathrm{p}^{1} \mathrm{P}_{1}$ lower laser state that Buchet estimated to be at $3951160 \mathrm{~cm}^{-1}$ or $489.88 \mathrm{eV}$. Using the Buchet value's for the energy levels one calculates the energy of the self-photopumped line to be $40.97 \mathrm{eV}$, which corresponds to a wavelength of $30.263 \mathrm{~nm}$. To determine a correction factor to apply to the MCDF calculations we assumed a value of $30.20 \mathrm{~nm}$ for the Ti line based on taking the upper range of the wavelength from Ref. 14 which is approximately midway between the mean values for the two experiments. This gives a correction of $0.859 \mathrm{eV}$ that we subtract from the MCDF calculated values to determine the wavelength shown in Table III. With more data one could create an energy dependent correction to the MCDF calculations as was done in Ref. 12. The calculated and measured values agree within $0.01 \mathrm{~nm}$ for $\mathrm{Fe}, \mathrm{Cr}$, and $\mathrm{V}$ and still differ by only $0.04 \mathrm{~nm}$ for Ti.

From Table III, the Ne-like $\mathrm{Cu}$ self-photopumped line is predicted at a wavelength of 18.95 $\mathrm{nm}$. The strong $4 \mathrm{~d}^{1} \mathrm{~S}_{0}-4 \mathrm{p}{ }^{1} \mathrm{P}_{1}$ laser line in Ni-like Mo would be an excellent calibration line to use for a precision measurement of the $\mathrm{Cu}$ line if one could get $\mathrm{Mo}$ and $\mathrm{Cu}$ to lase in the same plasma. To date we have not observed lasing on the self-photopumped line in Ne-like $\mathrm{Cu}$.

Table III. Wavelengths of the self-photopumped Ne-like x-ray laser lines measured in this work. The uncertainties in the last digit are given in parentheses. The monopole collisional reference lines used in the experiments are from ${ }^{\mathrm{c}} \mathrm{Ref} .19$.

\begin{tabular}{|c|c|c|c|}
\hline \multirow{2}{*}{ Ne-like } & $\begin{array}{c}\text { Reference line } \\
3 p^{1} \mathrm{~S}_{0}-3 \mathrm{~s}^{1} \mathrm{P}_{1}(\mathrm{~nm})\end{array}$ & \multicolumn{2}{|c|}{$\begin{array}{r}\text { Self-photopumped line } \\
3 \mathrm{~d}^{1} \mathrm{P}_{1}-3 \mathrm{p}^{1} \mathrm{P}_{1}\end{array}$} \\
\hline $\mathrm{Zn}$ & & & \\
\hline $\mathrm{Cu}$ & & & 17.93 \\
\hline $\mathrm{Ni}$ & & & 18.95 \\
\hline $\mathrm{Co}$ & $24.238^{\mathrm{c}}$ & $22.637(7)$ & 20.06 \\
\hline $\mathrm{Fe}$ & $25.495^{\mathrm{c}}$ & & 22.64 \\
\hline $\mathrm{Mn}$ & & $25.888(11)$ & 24.16 \\
\hline $\mathrm{Cr}$ & $28.546^{\mathrm{c}}$ & $27.873(10)$ & 25.89 \\
\hline $\mathrm{V}$ & $30.426^{\mathrm{c}}$ & $30.158(10)$ & 30.20 \\
\hline $\mathrm{Ti}$ & $32.621^{\mathrm{c}}$ & & 27.88 \\
\hline
\end{tabular}




\section{Summary}

The experiments on the self-photopumped lasing demonstrate that the list of elements that lase on the self-photopumped transition can be extended to include a number of new lines not reported to date. In particular, we have demonstrated lasing on the Ne-like $3 \mathrm{p}{ }^{1} \mathrm{~S}_{0} \rightarrow 3 \mathrm{~s}^{1} \mathrm{P}_{1}$ laser line for the first time for $\mathrm{V}, \mathrm{Cr}, \mathrm{Fe}$ and $\mathrm{Co}$ as well as on the Ni-like $4 \mathrm{~d}^{1} \mathrm{~S}_{0} \rightarrow 4 \mathrm{p}{ }^{1} \mathrm{P}_{1}$ line for $\mathrm{Ru}, \mathrm{Pd}$, and $\mathrm{Ag}$. The predicted characteristics of the self-photopumped lasing lines to be stronger than the neighbour electron-collision-pumped lines has been only observed so far in some shots in Ne-like Ti (see fig. 3 for example). We found a strong dependence on the mainto-second prepulse delay. The optimum delay shifts towards smaller delays with increasing atomic number Z. Time-resolved measurements showed that self-photopumped and monopole collision-pumped lasing emission occurs essentially simultaneously. Accurate wavelength measurements and calculations are shown to be in excellent agreement.

\section{Acknowledgments}

This work was supported by the Swiss National Science Foundation under contract number 200020_144380. The work of one author (J.N.) was performed under the auspices of the U.S. Department of Energy by Lawrence Livermore National Laboratory under Contract DEAC52-07NA27344.

\section{References}

[1] R.C. Elton, X-Ray Lasers (Academic, San Diego, 1990).

[2] B.A. Reagan et al., "High-average-power, 100-Hz-repetition-rate, tabletop soft-x-ray lasers at sub-15-nm wavelengths", Phys. Rev. A 89, 053820 (2014).

[3] J.E. Balmer, F. Staub, and F. Jia,'Soft-X-Ray Lasing down to $6.85 \mathrm{~nm}$ in Ni-Like Samarium", X-Ray Lasers 2012, Springer Proceedings in Physics 147 Chapter 5 (2014).

[4] J. Nilsen, B.J. MacGowan, L.B. Da Silva, and J.C. Moreno, "Prepulse technique for producing low-Z Ne-like x-ray lasers", Phys. Rev. A 48, 4682 (1993).

[5] R. Keenan, "High-Repetition-Rate Grazing-Incidence Pumped X-Ray Laser Operating at 18.9 nm”, Phys. Rev. Lett. 94, 103901 (2005).

[6] H. Fiedorowicz, A. Bartnik, Y. Li, P. Lu, and E. Fill, "Demonstration of Soft X-Ray Lasing with Neon-like Argon and Nickel-like Xenon Ions Using a Laser-Irradiated Gas Puff Target", Phys. Rev. Lett. 76, 415 (1996).

[7] P. V. Nickles, V. N. Shlyaptsev, M. Kalachnikov, M. Schnürer, I. Will, and W. Sandner, "Short Pulse X-Ray Laser at $32.6 \mathrm{~nm}$ Based on Transient Gain in Ne-like Titanium”, Phys. Rev. Lett. 78, 2748 (1997).

[8] J. Nilsen, H. Fiedorowicz, A. Bartnik, Y.L. Li, P.X. Lu, and E.E. Fill, "Selfphotopumped neonlike x-ray lasers", Opt. Lett. 21, 408 (1996).

[9] J. Nilsen, "Lasing on the $3 d \rightarrow 3 p$ neonlike $x$-ray laser transitions driven by a selfphoto-pumping mechanism" Phys. Rev. A 53, 4539 (1996).

[10] J. Nilsen, “Analysis of a picosecond-laser-driven Ne-like Ti x-ray laser", Phys. Rev. A 55, 3271 (1997). 
[11] J. Nilsen, "Design of a picosecond-laser-driven Ni-like Mo x-ray laser near $20 \mathrm{~nm}$ ", J. Opt. Soc. Am. B 14, 1511 (1997).

[12] J. Nilsen, J. Dunn, A.L. Osterheld, and Y.L. Li, "Lasing on the self-photopumped nickel-like $4 f^{1} P_{1} \rightarrow 4 d^{1} P_{1} x$-ray transition", Phys. Rev. A 60, R2677 (1999).

[13] J. Kuba, A. Klisnick, D. Ros, P. Fourcade, G. Jamelot, J. Miquel, N. Blanchot, and J. Wyart, "Two-color transient pumping in Ni-like silver at 13.9 and $16.1 \mathrm{~nm}$ ", Phys. Rev. A 62, 043808 (2000).

[14] Y. Wang, E. Granados, M.A. Larotonda, M. Berill, B.M. Luther, D. Patel, C.S. Menoni, and J.J. Rocca, "High-Brightness Injection-Seeded Soft-X-Ray-Laser Amplifier Using a Solid Target", Phys. Rev. Lett. 97, 123901 (2006).

[15] M.P. Kalachnikov, P.V. Nickles, M. Schnürer, W. Sandner, V.N. Shlyaptsev, C. Danson, D. Neely, E. Wolfrum, J. Zhang, A. Behjat, A. Demir, G. J. Tallents, P. J. Warwick, and C. L. S. Lewis, "Saturated operation of a transient collisional x-ray laser", Phys. Rev. A 57, 4778 (1998).

[16] F. Jia, F. Staub, M. Siegrist, and J.E. Balmer, "Analytic Study of Traveling-Wave Velocity Variation in Line Focusing Schemes of Plasma X-ray Lasers”, Appl. Opt. 53, 3247 (2014).

[17] F. Staub, C. Imesch, D. Bleiner, and J.E. Balmer, "Soft-x-ray lasing in nickel-like barium at $9.2 \mathrm{~nm}$ using the grazing-incidence scheme", Opt. Commun. 285, 2118 (2012).

[18] Y. Li, J. Nilsen, J. Dunn, and A.L. Osterheld, "Wavelengths of the Ni-like $4 d^{1} S_{0}-4 p^{1} P_{1}$ $x$-ray laser line”, Phys. Rev. A 58, R2668 (1998).

[19] J. Nilsen and J.H.Scofield, "Wavelengths of Neon-like 3p-3s X-ray Laser Transitions", Physica Scripta 49, 588-591 (1994).

[20] I. P. Grant, B. J. McKenzie, P. H. Norrington, D. F. Mayers, and N. C. Pyper, Comput. Phys. Commun. 21, 207 (1980).

[21] J-P Buchet, M-C Buchet-Poulizac, A. Denis, J. Desesquelles, M. Druetta, S. Martin, and J-F Wyart, J. Phys. B 20, 1709 (1987). 